\title{
Studies of the Morphological, Physiological, and Biochemical Characters of Actinomyces bovis
}

\author{
BY L. PINE \\ Department of Microbiology, Duke University Medical School, \\ Durham, North Carolina, U.S.A. \\ A. HOWELL, Jun. \\ National Institute of Dental Research, National Institutes of Health, \\ Public Health Service, U.S. Department of Health, Education and Welfare, \\ Bethesda 14, Maryland, U.S.A. \\ AND SARAH J. WATSON \\ Department of Microbiology, Duke University Medical School, Durham, \\ North Carolina, U.S.A.
}

(Received 20 April 1960)

\section{SUMMARY}

A study was made of 11 bovine strains of Actinomyces. These strains were compared with 15 human strains identified as Actinomyces israelii and Actinomyces naeslundii. Ten of the bovine strains constituted a homogeneous group identified as Actinomyces bovis. One of the bovine strains was identified as $A$. israelii.

The characteristics of Actinomyces bovis were the following: it failed to form a true mycelium in vitro; it had less tendency than $A$. israelii and $A$. naeslundii to form mycelial elements in lesions in animals into which it was inoculated. Characteristically it formed two types of colonies when first isolated from animals and when maintained in culture. These colonies were: (1) a smooth glistening transparent microcolony having an entire or furred edge; (2) a raised, opaque, rough colony having an entire or furred edge. The microcolonies of $A$. bovis were very characteristic on brain heart infusion agar and were easily differentiated from the mycelial colonies of $\boldsymbol{A}$. israelii and $\boldsymbol{A}$. naeslundii. Variation of the morphology of the colonies occurred rapidly in vitro as a result of genetic change and the medium used. When large, on certain media, the colonies of either the rough or smooth variants were sometimes indistinguishable from colonies of $A$. israelii or $A$. naeslundii, but were easily distinguishable on brain heart infusion agar. $A$. bovis was a catalase negative anaerobe which did not hydrolyse gelatin or casein; but in contrast to $A$. israelii and A. naeslundii it hydrolysed starch rapidly and completely when tested with $\mathrm{KI}+\mathrm{I}_{2}$ solution. A. bovis produced acid but no gas from starch but did not form acid or gas from xylose, raffinose, and mannitol, and did not reduce nitrate to nitrite. $A$. israelii did not form acid or gas from starch; it usually produced acid but no gas from xylose and mannitol, and occasionally produced acid but no gas from raffinose; it reduced nitrate to nitrite sometimes. $A$. naeslundii produced no acid or gas from starch; it produced acid but no gas from raffinose but not from xylose or mannitol, and it reduced nitrate to nitrite. 


\section{INTRODUCTION}

In a comparative study of Actinomyces spp. with strains of Lactobacillus bifidus, Pine \& Howell (1956) did not include bovine strains of $A$. bovis identical with those described by Erikson (1940) or Thompson (1950). Of the two bovine-type strains which had been obtained, one was lost and the second did not give satisfactory growth in the medium used. Repeated attempts to obtain known strains of $A$. bovis from other investigators were unsuccessful. In some cases cultures were obtained but these were either Corynebacterium species or cultures of Actinomyces identical with $A$. israelii. It was therefore considered possible that the limited acceptance of $A$. bovis as a separate species was due either to the failure of various investigators to recognize strains of $A$. bovis as described by Erikson (1940), or to the possibility that no real species differentiation was warranted. Since the only extensive comparative bacteriological study of $A$. bovis and $A$. israelii was done by Erikson (1940), it appeared to us that re-evaluation of the species $A$. bovis and $A$. israelii was in order. Consequently, 11 strains of Actinomyces from typical cases of lumpy jaw in cows were obtained from other workers or isolated directly (Pine \& Watson, 1959). These cultures have now been critically studied in regard to cellular and colonial morphology, physiology and fermentative ability. Comparisons have been made with strains now recognized as $A$. israelii and $A$. naeslundii either directly or on the basis of the results obtained previously (Pine \& Howell, 1956; Howell, Murphy, Paul \& Stephan, 1959). These investigations, in our opinion, support the taxonomic existence of the species $A$. bovis, as originally proposed by Erikson (1940).

\section{METHODS}

\section{Strains of Actinomyces spp. used}

The strains of Actinomyces isolated from human sources are those given in Table 1. All cultures were maintained on the maintenance medium of Pine \& Watson (1959), with the exception of one rough variant of $A$. bovis $(A$. bovis $\mathrm{P} 2 \mathrm{R}$ ) which was cultured on a $1+1(v / v)$ mixture of brain heart infusion agar (Difco) + maintenance medium.

Isolation of single microscopic colonies of Actinomyces bovis

The medium generally used for primary isolations, purification, and studies of cultural variation in the strains of Actinomyces bovis was the maintenance medium as a liquid or with $\mathbf{0 . 7}$ or $\mathbf{1 . 5} \%(\mathrm{w} / \mathrm{v})$ agar. In most cases Garrod's medium and brain heart infusion agar with and without sheep's blood $(10 \%, \mathrm{v} / \mathrm{v})$ were also used for primary isolation as described previously (Pine \& Watson, 1959). The composition of Garrod's medium was : beef extract 3.0 g., $\mathrm{NaCl} 5$ g., Bactopeptone $10 \mathrm{~g}$., soluble starch $1.0 \mathrm{~g}$., and $20 \mathrm{~g}$. agar per litre of medium (Prof. L. P. Garrod, personal communication). The incubation temperature used was $37^{\circ}$ unless otherwise stated.

To prepare the inoculum for isolation from clinical material, mycelial granules were picked from the pus and transferred to a tube of sterile distilled water. The tube was shaken vigorously, the granules allowed to settle to the bottom, and the supernatant liquid withdrawn with a sterile pipette. This washing procedure was 
repeated at least twice. After the final washing the granules were ground up in the residual fluid by using a heavy tight-fitting, sterile glass rod. The homogenate was then streaked on the isolation media and the plates incubated in $5 \%(\mathrm{v} / \mathrm{v})$ $\mathrm{CO}_{2}+95 \%(\mathrm{v} / \mathrm{v}) \mathrm{N}_{2}$. The plates, which were examined daily for 3-5 days, were

\begin{tabular}{|c|c|c|}
\hline \multicolumn{3}{|c|}{ Human strains } \\
\hline 699 & Lacrimal canaliculitis & $\begin{array}{l}\text { Duke University Medical School, Mycology } \\
\text { Section, Durham }\end{array}$ \\
\hline OS 131 & Lacrimal canaliculitis & $\begin{array}{l}\text { Duke University Medical School, Mycology } \\
\text { Section, Durham }\end{array}$ \\
\hline 843 & Actinomycosis of the upper jaw & $\begin{array}{l}\text { Duke University Medical School, Mycology } \\
\text { Section, Durham }\end{array}$ \\
\hline 534 & Actinomycosis of the elbow & $\begin{array}{l}\text { Duke University Medical School, Mycology } \\
\text { Section, Durham }\end{array}$ \\
\hline 895 & Thoracic actinomycosis & $\begin{array}{l}\text { Duke University Medical School, Mycology } \\
\text { Section, Durham }\end{array}$ \\
\hline 261 & Gingival scrapings & $\begin{array}{l}\text { Dr Ada Clark and Dr Solon A. Ellison, } \\
\text { Department of Bacteriology, College of } \\
\text { Physicians and Surgeons, Columbia Uni- } \\
\text { versity }\end{array}$ \\
\hline 262 & Cervico-facial actinomycosis & $\begin{array}{l}\text { Dr Ada Clark and Dr Solon A. Ellison, } \\
\text { Department of Bacteriology, College of } \\
\text { Physicians and Surgeons, Columbia Uni- } \\
\text { versity }\end{array}$ \\
\hline 263 & Cervico-facial actinomycosis & $\begin{array}{l}\text { Dr Ada Clark and Dr Solon A. Ellison, } \\
\text { Department of Bacteriology, College of } \\
\text { Physicians and Surgeons, Columbia Uni- } \\
\text { versity }\end{array}$ \\
\hline 282 & Mandibular abscess & $\begin{array}{l}\text { Dr Per Holm, State Serum Institute, } \\
\text { Copenhagen }\end{array}$ \\
\hline 283 & Mandibular abscess & $\begin{array}{l}\text { Dr Per Holm, State Serum Institute, } \\
\text { Copenhagen }\end{array}$ \\
\hline 286 & Gingival scrapings & $\begin{array}{l}\text { Dr Robert J. Fitzgerald, National Institute } \\
\text { of Dental Research, Bethesda }\end{array}$ \\
\hline 287 & Cervico-facial actinomycosis & $\begin{array}{l}\text { Dr Solon A. Ellison, Department of Bacterio- } \\
\text { logy, College of Physicians and Surgeons, } \\
\text { Columbia University }\end{array}$ \\
\hline 279 & Sinus following tooth extraction & $\begin{array}{l}\text { Dr Luther Thompson, Section on Bacterio- } \\
\text { logy, Mayo Clinic, Rochester, Minn. }\end{array}$ \\
\hline 295 & Human pleural fluid & ATCC 10048 \\
\hline 296 & Atypical actinomycosis of the ankle & ATCC 10049 \\
\hline
\end{tabular}

Animal strains

P1S; P2S, P3S, P4S and variants; lumpy Isolated in present work

jaw in cows

A1, A8, A9, A 10, A11, A12; lumpy jaw in cows

Dr Libero Ajello and Dr William Kaplan, U.S.P.H. Communicable Disease Center, Chamblee, Ga.

A 601. Lumpy jaw in cow

DrEsther Meyer, Department of Bacteriology, College of Medicine, University of Illinois, Chicago, Ill.

invariably found to be heavily covered with colonies of Actinomyces bovis; a few streptococcal colonies were occasionally observed. However, as repeated isolations were made from the same sample of frozen pus (Pine \& Watson, 1959) greater numbers of contaminating colonies were obtained. To purify or to pick variant 
colonies of pure cultures, the inoculum was streaked on agar plates and incubated for $24-48 \mathrm{hr}$. The plates were then examined with the scanning objective of the microscope (total magnification, $\times 75$ ). When a colony was chosen for transfer, it was centred in the microscopic field, and the objective was swung to low power $(\times 150)$. The diaphragm of the light source was decreased until the diameter of the circle of light was only slightly larger than that of the microcolony. The substage condenser was focused so that Koehler illumination resulted, i.e. the image of the light source was in focus on the surface of the agar plate. The objective was raised from the plate and, keeping the plate in place, the circle of light was outlined at its circumference by stabbing the agar successively with a stiff inoculating needle which had been sharpened to a fine point and bent at $\mathrm{a} 90^{\circ}$ angle. The colony was then re-examined under the scanning objective to ascertain that only the desired colony was circumscribed and that no neighbouring colonies had been touched. The plate was removed from the microscope stage and the small disk of agar carrying the colony was picked from the plate and transferred to a tube of maintenance liquid medium. The plate was re-examined to make certain that neighbouring colonies had not been disturbed in picking the agar disk.

The microcolonies of Actinomyces spp. adhered to the agar disks tenaciously. The disks were observed daily at the bottom of the tube of broth by using a hand lens and the original colonies generally were seen to grow into single large colonies which separated from the agar with shaking. When such disks showed multiple colonies or when they showed growth emanating from other points of the agar disk, they were discarded. In primary isolation from infected cow heads, cultures from single colonies were restreaked and single colonies picked again. This was repeated a third time before stock cultures were made.

General cultural and chemical methods. The procedures for the growth and preparation of inocula for all the cultures and measurements of growth were those described previously (Pine \& Howell, 1956). To make direct comparisons with the human strains of Actinomyces (Pine \& Howell, 1956) all physiological studies were made by using the liquid defined medium + starch + Casitone (Difco) of Pine \& Howell (1956), or in some cases by using the maintenance medium. However, cultural and morphological studies were also done by using Garrod's medium and brain heart infusion agar (Difco), with and without $10 \%(\mathrm{v} / \mathrm{v})$ blood; fluid thioglycollate (Baltimore Biological Laboratory), and thioglycollate agar. The anaerobic and aerobic seals used, with or without carbon dioxide, and all chemical, physiological and fermentation methods were as described previously (Pine \& Howell, 1956). All plates were incubated in an atmosphere of $5 \%(\mathrm{v} / \mathrm{v}) \mathrm{CO}_{2}+95 \%(\mathrm{v} / \mathrm{v}) \mathrm{N}_{2}$.

All strains were tested for pathogenicity in hamsters (Hazen \& Little, 1958). Cultures for animal inoculation were grown in $5 \mathrm{ml}$. maintenance medium for 48-72 hr. The organism was centrifuged and the sediment homogenized in $5 \mathrm{ml}$. sterile distilled water. Each animal, aged 4-6 weeks, was inoculated with the homogenized suspension intraperitoneally with $0.5 \mathrm{ml}$. and intradermally on each side of the abdomen with $\mathbf{0 . 2} \mathrm{ml}$. The inoculated animals were observed for 10-30 days. During this time, abscesses which formed in the skin were drained by first rubbing the surface of the skin with ethanolic iodine solution and then puncturing with a needle. Gram stains of the pus were made and examined for the presence of typical actinomycotic mycelial elements. Such lesions were drained on successive occasions 
until they healed spontaneously or until the animal was sacrificed. Generally the abscesses formed a 'head' by the 5th to 7th day, ruptured, and healed by the 10th day. In the experiment presented in Table 3, animals were inoculated intraperitoneally and intradermally and re-inoculated 7 days later. All animals were then sacrificed 30 days after the first inoculation. Other methods or procedures when used are given in the text.

\section{RESULTS}

\section{Morphological and cultural characteristics of bovine strains of Actinomyces}

Of the 11 strains of Actinomyces isolated from cattle, one strain, A601, was identical in its characteristics with Actinomyces israelii as described by Howell et al. (1959). It served, therefore, as a comparative control and will be discussed later in regard to specific experiments. Ten strains, however, formed a homogeneous group which were essentially identical. These strains are referred to as $A$. bovis. Of the strains of $A$. bovis, only those isolated from cases $\mathrm{P} 1, \mathrm{P} 2, \mathrm{P} 3$ and $\mathrm{P} 4$ were studied from their initial isolation from infected cows (Pine \& Watson, 1959). Since these strains encompassed the greatest range observed of variation in colonial morphology, it is considered important to describe these cultures completely. The conclusions based on their study were found to apply equally to the remaining strains.

\section{Characteristics of clinical material from cases $\boldsymbol{P} 1, \boldsymbol{P}_{2}, \boldsymbol{P} 3$ and $\boldsymbol{P}_{4}$}

The clinical specimens from which the $\mathbf{P}$ strains were isolated were cow heads exhibiting typical lumpy jaw. The upper jaws showed tumour-like enlargements of the bone which were invaded by multiple draining sinuses or which contained large abscesses filled with caseous material. When the pus from such sinuses was suspended in sterile distilled water and shaken, numerous 'sulphur' granules immediately sedimented. These, when mounted in $10 \%(\mathrm{w} / \mathrm{v}) \mathrm{KOH}$ solution, had a hard gritty consistency when rubbed and crushed between the coverslip and glass slide. When they were observed under low power of the microscope, the actinomycotic granules had a typical dense outline as shown in Pl. 1, fig. 1, and contained numerous densely packed 'clubs' (Pl. 1, fig. 2). When stained by Gram's method, Grampositive actinomycotic filaments were seen at the borders of the dense central portions of the actinomycotic granule (Pl. 1, fig. 3).

\section{Morphological aspects of colonies on primary isolation and of laboratory strains of Actinomyces bovis}

Previous reports of other workers (Wright, 1905; Emmons, 1935), and our own experience, had emphasized the importance of observing the highly diagnostic spider-like microcolonies of Actinomyces (e.g. Pl. 1, fig. 4). On the isolation plates of strain P2 such colonies were found, although these were extremely minute (PI. 2, fig. 13). However, for cases P1, P3 and P4 no such colonies were found, although repeated isolations were made at several month intervals from frozen pus (Pine \& Watson, 1959). In the descriptions which follow, it is emphasized that the distinction between $R$ and $S$ colonies was based on the microscopic appearance of 24-48 hr. colonies as viewed by transmitted and reflected light. Smooth colonies were typically those shown in $\mathrm{Pl}$. 1, fig. 5, and $\mathrm{Pl}$. 2, fig. 10, while the term rough colony 
was used to designate the range of forms depicted in Pl. 1, fig. 6, Pl. 2, fig. 13 (spider forms), and Pl. 4, fig. 28. The differentiation of smooth and rough forms by transmitted and reflected light is shown in Pl. 4, figs. 26 and 27.

All the colonies from case P1 were small, circular, and with entire edges. The surfaces of the colonies were smooth, slightly convex, and moist in appearance but when photographed were similar to those shown in Pl. 2, fig. 11. These smooth colonies of case P1 were, on primary isolation, similar in appearance with smooth colonies of P2, P3 and P4 isolated subsequently and with the colonies observed initially from the laboratory strains A 1, A 10 and A11. When these smooth colonies were observed by transmitted light, they showed characteristically either a very dense 'hyphal' formation in the centre (Pl. 1, fig. 5) or a slightly concave centre with a small button. Consequently, the latter colonies generally had the appearance of a small torus ( $\mathrm{Pl} .2$, fig. 10) by transmitted and reflected light. In the case of some strains, they resembled flat or slightly convex circular disks having a small projection in the centre (Pl. 2, fig. 12). The very small smooth colonies of several strains were of such a nature that clear sharp photographic images could not be obtained by reflected light (Pl. 2, fig. 11). This was attributed to the very mucoid nature of the surface of the colony at this time, or to the possibility that the edges of the colony merged so gradually with the agar surface that no sharp line of demarcation was formed, As these colonies become larger, however, or in the case of smooth colonies of other strains, the surface and edge of the colonies became more distinct (Pl. 2, fig. 16). In texture, the small smooth colonies were extremely soft and were easily broken when touched with an inoculating needle, while the larger smooth colonies maintained their structure when pushed short distances with the needle.

In case $\mathbf{P 1}$, only one type of colony, the smooth colony, was observed on primary isolation. However, on the primary isolation plates of cases $P 3$ and P4, a second type of colony, the rough colony, was observed. When small and viewed by transmitted light, this colony was much more dense and more irregular in its outline than the smooth colony, and presented a rough granular appearance (Pl. 1, fig. 6; Pl. 4, fig. 27). Similar colonies were also observed in the laboratory cultures A8, A9 and A 12. As shown by oblique lighting, when rough colonies enlarged, they became opaque and considerably more elevated than the smooth colonies, although they continued to be circular in form (PI. 1, fig. 7; Pl. 4, fig. 26). The surface of such colonies was generally smooth, but in many instances their surface became folded and irregular (Pl. 4, figs. 28, 30) or often resembled an inverted raspberry. When such a colony was picked for transfer, it was easily removed as a whole. These colonies were quite hard and maintained their colonial morphology through considerable manipulation. However, when these rough colonies were examined under oil immersion, contrary to the expectation of finding interwoven mycelial elements, only masses of diphtheroid organisms were observed (Pl. 1, fig. 9).

When the isolation plates of case $\mathrm{P} 2$ were studied, the typical young smooth colonies observed on the isolation plates of the other cases were found (Pl. 2, figs. 12, 16). However, in this case the rough colonies were replaced by spider forms (P2 R; Pl. 2, fig. 13) which rapidly coiled (Pl. 2, fig. 14) to form smooth, round, opaque colonies like those of P 2S (Pl. 2, figs. 16, 17). Upon isolation of the rough colony, it was found that it did not grow significantly upon a second transfer unless a medium was used which consisted of a mixture of brain heart infusion agar and maintenance 
medium. Even then its growth was extremely slow and limited and required 7-10 days to reach a maximum as compared to $18-24 \mathrm{hr}$. required by the smooth colonies. Brain heart infusion agar did not support growth for more than two transfers. From Pl. 2, fig. 17, it is seen that the rough colonies of strain $\mathbf{P 2}$ are circular and raised, differing somewhat from the rough colonies of $\mathrm{P3}$ and $\mathbf{P} 4$ in the surface texture and in being more convex (Pl. 4, fig. 28).

Repeated isolations were made from cases $\mathbf{P 1}, \mathbf{P 2}, \mathbf{P 3}$ and $\mathbf{P} 4$ to verify the presence or absence of spider-like colonies. Of these only P2 exhibited spider colonies. Representative colonies of each type from the various strains were picked and cultured by the methods described earlier in this paper. From case P1, only one stock culture was made, i.e. Actinomyces bovis P1S; from case P2 a smooth colony subculture, $A$. bovis, $\mathrm{P} 2 \mathrm{~S}$, and a rough (spider) colony subculture, $A$. bovis, $\mathrm{P} 2 \mathrm{R}$; from case P3, a smooth colony subculture, $A$. bovis $\mathrm{P3S}$, and a rough colony subculture, $A$. bovis $\mathrm{P3R}$, were made; while from case $\mathrm{P} 4$, only a single culture, $A$. bovis $\mathbf{P} 4 \mathrm{R}$, was made, even though smooth colonies were observed.

\section{Cultural characteristics of Actinomyces bovis in liquid media}

Several experiments with liquid media were done to determine the effect of the medium and conditions of growth on the cultural characteristics of the strains of Actinomyces bovis. In these experiments the Casitone containing medium, the defined medium + casein hydrolysate, and the maintenance medium were used with aerobic or anaerobic carbon dioxide seals (Pine \& Howell, 1956). Organisms in such tubes of liquid medium settled to the bottom; the growth was either mucoid, i.e. forming spiralling viscous ropes when the contents of the tubes were swirled, granular, i.e. forming bread-crumb colonies similar to those described for $\boldsymbol{A}$. israelii, or flaky, i.e. resembling flakes of snow when the tubes were shaken. In continuous transfer, the types of growth of a single strain in any one medium could vary from mucoid to flaky, to granular. Such changes were observed to occur in all of the media, although growth in the casein hydrolysate medium was slow (maximum growth in 3-5 days) and tended to become granular in the presence of air and carbon dioxide. On the other hand, anaerobically, growth in the maintenance medium was generally mucoid or flaky and reached its maximum within 2-3 days.

\section{Cellular morphology of Actinomyces bovis}

With the exception of isolate P2R the cellular morphology of the Actinomyces bovis strains was uniformly diphtheroid in liquid media or on agar media (Pl. 3, fig. 20), and, in general, distinguishable from the usual rods observed for most strains of A. israelii (Pl. 3, fig. 18) or A. naeslundii, as recently shown by Howell et al. (1959). The diphtheroid forms of $A$. bovis, however, did resemble the diphtheroid forms of $\boldsymbol{A}$. israelii (Pl. 3, fig. 19) isolated from lacrimal infections (Pine \& Hardin, 1959).

From the usual agar media, it was difficult to ascertain the true mycelial nature of the bovine isolates in their initial stages of growth, although branching diphtheroid cells were invariably present. To demonstrate the different morphological types and, in particular, the mycelial phases of growth, the strains were grown in liquid maintenance medium containing $0.05 \%(\mathrm{w} / \mathrm{v})$ agar. The colonies were then drawn into capillary pipettes and transferred to glass slides, heat fixed and Gram stained or mounted in lactophenol cotton-blue mounting medium (Conant et al. 
1954). When mounted in lactophenol, the colonies characteristically showed compact masses of growth from which one or two filaments extended (Pl. 3, fig. 24), but which did not demonstrate the true mycelium as first shown by Wright (1905) for human isolates under similar conditions. When the culture was of a rough strain, these compact masses retained their structure, whereas smooth strains tended to disintegrate into individual diphtheroid elements.

When stained by Gram's method, very young single colonies of the rough forms often showed a definite mycelium (Pl. 3, fig. 25), which rapidly became unapparent with further growth. Gram stains of the smooth strains grown in maintenance liquid medium $+0.05 \%(\mathrm{w} / \mathrm{v})$ agar often showed an indefinite cellular structure (Pl. 3, fig. 22), and the presence of many bizarre forms which were similar if not identical with those described by Sundman \& Björksten (1958) for Lactobacillus bifidus. As the diphtheroid forms of the rough and smooth strains entered the maximum stationary phase of growth, they became partially Gram negative and often exhibited multiple round metachromatic granules distributed within the cells (Pl. 3, fig. 21). As shown in Pl. 3, fig. 23, the morphology of the mycelial Actinomyces bovis, strain P2R, was similar to that found with the typical $A$. israelii forms (Pl. 3, fig. 18) but the bacillary elements were finer.

\section{Factors influencing colonial morphology of strains of Actinomyces bovis}

Within several months after their initial isolation and purification it became evident that various strains of Actinomyces bovis were changing in their colonial morphology. Rough cultures exhibited a mixture of smooth and rough colonies and occasionally smooth cultures would show rough colonies. By direct experiment, or indirectly from general observations made throughout this work, several factors were observed to effect the kind of colony which might result from a purified strain. These factors were the strain used, medium used, number of transfers undergone by the strain, and the effect of animal inoculation. These results are presumably an expression of selection due to nutritional factors, genetic variation, or both.

Colony morphology as related to strain characteristics. Because of the extreme morphological diversity of strains P2S and P2R, it was thought to be desirable to establish, if possible, the origin of the two types. Either a mixed infection with Actinomyces israelii and $A$. bovis had occurred in the cow or one form was a variant of the other. Consequently, the purity and the stability of the two forms were established. After three consecutive transfers consisting of streaking and re-isolation of single microcolonies, a strain of the $\mathbf{P 2}$ rough spidery colony type (P2 Rb) was obtained which did not form smooth colonies. No change in the morphology or character of this culture has been observed in a period of 2 years. In the case of the smooth form, it was found that single colonies of P2S formed only smooth colonies when restreaked and a stock culture P2S was made from these. Likewise, no changes in the colony characteristics of this strain were observed during 2 years. However, recently rough colonies similar to those seen in $\mathrm{Pl}$. 1, fig. 6, have been seen in P2S.

With the exception of strains P2S and P2R, most of the strains of Actinomyces bovis showed a ready conversion of rough to smooth or in a few strains a much more limited conversion of smooth to rough. In attempts to induce such a conversion in the P2R cultures, strain P2 R and several single colony isolates from it were grown 
in maintenance liquid medium + brain heart infusion, or in thioglycollate broth. When growth was heavy, a loopful of inoculum was streaked on maintenance or brain heart infusion agar plates. The colonies which appeared were identical with the stock cultures from which they originated. Rapid passage for six consecutive transfers in thioglycollate broth and in the mixture of maintenanceliquid medium + brain heart infusion did not induce any permanent change in colony morphology, even though cellular morphology was observed to vary from purely mycelial strands to diphtheroid cells. Similarly, rapid transfer of P2S in maintenance broth produced cells which when streaked on maintenance agar plates formed rather granular smooth colonies. These were, nevertheless, quite different from the spidery rough colonies with which they had been associated in the cow.

In addition to the above experiment, each of 10 plates were inoculated with $\mathbf{0 \cdot 2}$ ml. of a maintenance liquid culture of $\mathrm{P} 2 \mathrm{~S}$ and 10 plates with $0.2 \mathrm{ml}$. of similar rough $\mathbf{P} 2 \mathrm{R}$ cultures. Critical examination of all plates still failed to demonstrate any colonies which indicated a mutation of $P 2 R$ to $P 2 S$ or vice versa.

Stock cultures of the other strains (P1S, P3 R, P 3S, P 4R), which had been purified by picking a single microcolony for further propagation, did not retain their colonial homogeneity. For example, after being transferred at monthly intervals during one year, the stock culture of P3R was streaked on maintenance medium agar. As shown (Pl. 4, fig. 28) the colonies which developed were a mixture of smooth and rough colonies, whereas a similar streaked plate of P3S had smooth colonies only (Pl. 4, fig. 29). From a streak plate of P3 R, 6 smooth colonies and 6 rough colonies were picked. Each was grown in maintenance liquid medium and each culture was streaked on agar plates. On the resulting plates, only smooth colonies were found from the P3S culture. On the plates inoculated with the rough cultures, from 1 to 15 smooth colonies were found. A rough colony was picked from such a plate, and a stock culture (P3Rbc) was made. Subsequently, maintenance of this culture resulted in a gradual increase in the ratio of smooth:rough colonies, whereas continued transfer of P3Sb (made from a smooth colony of the P3S plate) showed a small but definite gain in the rough variant. Of the strains studied, the change was generally rough to smooth, although in the case of strain A11, the reverse was true. Strain P1S, which was originally isolated as a pure smooth colony, was found to be predominantly a rough culture after 2 years maintenance.

As shown in Table 2, the direction of the change in colonial morphology depended upon the strain tested. In this experiment stock cultures of the rough and smooth strains, all of which originated from single microcolonies, were restreaked on two plates of brain heart infusion agar and two plates of maintenance medium agar. The ratio of smooth colonies to rough colonies, or vice versa, in eight separate fields of each plate was determined. It is concluded that changes in the P3 strains are best expressed diagrammatically as P3R $\longleftarrow$ P3S and in the A11 strains as A11S A 11R. Again, in the case of the P2 strains, a change of colonial morphology in either direction was not observed.

Effect of medium on colonial morphology. As shown in Table 2, the medium used may affect the relative number of microscopic smooth or rough colonies. It was observed during the primary isolation of the bovine strains that colonies on brain heart infusion agar were uniformly smooth although very small. Isolations made on maintenance medium agar, however, showed some rough colonies. 
Different media may also affect the gross colonial morphology of a given strain. For example, a direct comparison of the effect of several media on colonial morphology was made with rough and smooth strains of Actinomyces bovis. As shown in Pl. 4, fig. 30, large colonies of P3S on thioglycollate agar had a highly irregular surface, whereas on maintenance medium agar the colony was circular with slight furrowing of the smooth surface (Pl. 4, fig. 31). Strain Al1 often formed only smooth colonies on brain infusion agar, whereas the same inoculum streaked on maintenance medium agar formed smooth and rough colonies. It is emphasized that the large rough colonies of $A$. bovis may often be identical to those of $A$. israelii and $A$. naeslundii as depicted by Howell et al. (1959).

Effect of animal inoculation on colonial morphology. Sixteen hamsters were inoculated with strain $\mathbf{P 2 S}$ in several different experiments; isolation plates made from the pus of one animal in an early experiment showed many P2R colony types. However, pus from two other animals of later experiments showed only four rough

Table 2. Relative proportion of rough and smooth colonies of Actinomyces bovis found on streaked plates 6 months after single colony isolation

Two plates of each medium brain heart infusion agar (Difco); maintenance agar (Pine \& Watson, 1959) were made for each strain. Inoculum was taken from stock cultures with a loop, suspended in a few drops of water, and streaked on the agar plates. Plates were incubated 5 days in a $5 \% \mathrm{CO}_{2}+95 \% \mathrm{~N}_{2}$ atmosphere at $37^{\circ}$. Plates were examined with a microscope using scanning objective $(\times 5)$ and wide field oculars $(\times 15)$. Eight different fields were counted per plate.

\begin{tabular}{lcc} 
& \multicolumn{2}{c}{ Ratio of S:R on } \\
\cline { 2 - 2 } Strain & BHI & Maintenance \\
P3S & $27: 1$ & $27: 1$ \\
P3R & $7: 3$ & $6: 7$ \\
A11S & $1: 10$ & $1: 5$ \\
A11 & $1: 37$ & $1: 40$ \\
P2S & $500: 0$ & $500: 0$ \\
P2R & $0: 500$ & $0: 500$
\end{tabular}

colonies in a total of 24 streaked plates which were heavily covered with colonies of P2S. In several experiments in which hamsters were inoculated with P2R, only the original type of spidery colony was obtained.

Other strains of Actinomyces bovis also showed increase of smooth to rough colonies in the animal. In one experiment (Table 3), cultures of various strains were grown in maintenance medium broth; two loopfuls of medium were then streaked on duplicate plates of brain heart infusion agar and of maintenance medium agar. The remainder of each culture was used to inoculate one hamster per strain. Pus was taken from the skin abscesses formed initially or from internal abscesses observed at autopsy 1 month after inoculation. The pus was streaked on duplicate plates of brain heart infusion agar and maintenance medium agar and Gram stains were made to examine for mycelium in the pus. As seen from Table 3 the initial liquid cultures of strains P1S, P3R, A10, A 11, and A 12 consisted of smooth, or mixed smooth and rough populations. However, upon the isolation from hamsters, the colonies obtained were predominantly rough. On the other hand, strains P2S and P3S did not show this propensity for smooth to rough increase. 


\section{Relative pathogenicity of Actinomyces bovis and human strains of Actinomyces}

In Pl. 4, figs. 32 and 33, it is seen that Actinomyces bovis strains formed typical actinomycotic branching mycelial elements when inoculated into animals. However, as indicated in Table 3, the ability of these strains to form mycelium in the animal is apparently much more limited than that of the human strains of Actinomyces.

Table 3. Variation of colony morphology of Actinomyces spp. as a result of hamster inoculation

Growth of inoculum was observed on agar plates within $24-48 \mathrm{hr}$. by transmitted light (see text). S-smooth Actinomyces bovis type of colony, $\mathbf{R}$-rough $A$. bovis type of colony, $\mathrm{N}-A$. naeslundii type of colony, I-A. israelii type of colony. Relative amount of mycelial elements formed was observed by Gram stains of pus removed from skin lesions 7-15 days after inoculation. Pathology was observed at autopsy 21 days to 1 month after inoculation. Colony type on isolation on maintenance agar was observed on plates streaked with pus from skin lesions taken 7-15 days after inoculation.

\begin{tabular}{|c|c|c|c|c|c|}
\hline \multirow[b]{2}{*}{ Strain } & \multicolumn{2}{|c|}{ Colony type on } & \multirow{2}{*}{$\begin{array}{l}\text { Relative } \\
\text { amount } \\
\text { of } \\
\text { mycelial } \\
\text { elements } \\
\text { formed }\end{array}$} & \multirow{2}{*}{$\begin{array}{l}\text { Pathology at } \\
\text { autopsy }\end{array}$} & \multirow{2}{*}{$\begin{array}{c}\text { Colony type } \\
\text { on isolation } \\
\text { on maintenance } \\
\text { agar }\end{array}$} \\
\hline & BHI & Maintenance & & & \\
\hline P1S & $\mathbf{S}$ & $\mathbf{S}$ & +1 & 2 large abscesses in skin & $\mathbf{S}+\mathbf{R}$ \\
\hline P2R & $\mathbf{I}$ & $\mathbf{I}$ & +1 & 1 large abscess in skin & $\mathbf{I}$ \\
\hline P2S & $\mathbf{S}$ & $\mathbf{S}$ & 0 & 1 small abscess in skin & $\mathbf{S}$ \\
\hline P3S & $\mathbf{S}$ & $\mathbf{S}$ & 0 & None & $\mathbf{S}$ \\
\hline P3R & $\mathbf{S}+\mathbf{R}$ & $\mathbf{S}+\mathbf{R}$ & $\mathbf{0}$ & None & $R+$ few $S$ \\
\hline $\mathbf{P 4 R}$ & $S+$ few $R$ & $\mathbf{S}$ & +2 & None & $S+$ few $R$ \\
\hline A 10 & S+few $R$ & $\mathbf{S}+\mathbf{R}$ & 0 & None & $\mathbf{R}+$ few $\mathbf{S}$ \\
\hline A11 & $\mathbf{S}+\mathbf{R}$ & $\mathbf{S}+\mathbf{R}$ & +1 & $\begin{array}{l}1 \text { small abscess in peri- } \\
\text { toneal wall }\end{array}$ & $\mathbf{R}$ \\
\hline A 12 & $\mathbf{S}+\mathbf{R}$ & $\mathbf{S}+\mathbf{R}$ & +1 & $\begin{array}{l}\text { Several small abscesses in } \\
\text { peritoneal wall }\end{array}$ & $\mathbf{R}$ \\
\hline 279 & $\mathbf{N}$ & $\mathbf{N}+\mathbf{S}$ & +5 & $\begin{array}{l}\text { Multiple abscesses in } \\
\text { mesenteries }\end{array}$ & $\mathbf{N}$ \\
\hline 286 & $\mathbf{S}$ & $\mathbf{N}$ & +1 & None & $\mathbf{N}$ \\
\hline 296 & $\mathbf{N}$ & $\mathbf{I}$ & +5 & None & Not done \\
\hline 295 & I & $\mathbf{I}$ & +5 & $\begin{array}{l}\text { Several small abscesses in } \\
\text { body wall }\end{array}$ & I \\
\hline 261 & Not done & Not done & . & $\begin{array}{l}\text { Single small abscess in } \\
\text { mesenteries }\end{array}$ & Not done \\
\hline 262 & $\mathbf{N}$ & $\mathbf{N}$ & +5 & $\begin{array}{l}\text { Few small abscesses in } \\
\text { mesenteries }\end{array}$ & I \\
\hline 263 & $\mathbf{N}$ & $\mathbf{N}$ & +5 & $\begin{array}{l}\text { Single small abscess in } \\
\text { body wall }\end{array}$ & $\mathbf{I}$ \\
\hline 282 & Not done & Not done & +5 & $\begin{array}{l}\text { Few abscesses in mesen- } \\
\text { teries; massive abscesses } \\
\text { in peritoneum }\end{array}$ & $\mathbf{I}$ \\
\hline 283 & $\mathbf{I}$ & $\mathbf{I}$ & +5 & Single abscess in body wall & $\mathbf{I}$ \\
\hline 287 & - & $\mathbf{I}$ & 0 & Single abscess in body wall & Not done \\
\hline 534 & $\mathbf{I}$ & $\mathbf{I}$ & +3 & $\begin{array}{l}1 \text { large caseous abscess in } \\
\text { body wall, sulphur granules }\end{array}$ & $\mathbf{I}$ \\
\hline 895 & $\mathbf{I}$ & $\mathbf{I}$ & +5 & $\begin{array}{l}\text { Few abscesses in mesen- } \\
\text { teries; few abscesses in } \\
\text { peritoneal wall }\end{array}$ & I \\
\hline 699 & $\mathbf{I}$ & $\mathbf{I}$ & +5 & $\begin{array}{l}\text { Several large abscesses in } \\
\text { internal organs }\end{array}$ & I \\
\hline OS 131 & $\mathbf{I}$ & $\mathbf{I}$ & +5 & $\begin{array}{l}\text { Several large abscesses in } \\
\text { internal organs }\end{array}$ & \\
\hline
\end{tabular}


It was generally difficult to find Gram-positive filaments in an animal inoculated with $A$. bovis unless an abscess formed which remained for 2 weeks or more (Table 3 ). All bovine strains tested, however, have at one time or another formed lesions containing typical mycelial elements when inoculated into animals. On the other hand, one can invariably observe long mycelial branching forms of $A$. israelii or $A$. naeslundii strains in young lesions, even though the lesion is short-lived and heals spontaneously. As shown by Table 3, many of the human strains of Actinomyces produced abscesses which were present 21 days to 1 month after inoculation, while only a few of the bovine strains did so.

\section{Physiological and biochemical characteristics of bovine strains of Actinomyces}

Characteristics of growth. Excepting strains A601 and P2R, all strains had a relatively high rate of growth, reaching maximum amount of growth within 30-36 hr. in Casitone containing liquid medium. This rate of growth is not as rapid as that

Table 4. Effect of size of inoculum on growth of bovine strains of Actinomyces

Maximum growth expressed as optical density obtained in $\boldsymbol{\gamma}$ days with continuous shaking. Carbon dioxide was supplied as a $\mathrm{Na}_{2} \mathrm{CO}_{3}+\mathrm{KH}_{2} \mathrm{PO}_{4}$ or $\mathrm{Na}_{2} \mathrm{CO}_{3}+$ pyrogallol seal. $0.05 \mathrm{ml}$. of inoculum was used per tube containing $5 \mathrm{ml}$. of casitone broth.

\begin{tabular}{|c|c|c|c|c|c|}
\hline \multirow[b]{2}{*}{ Strain } & \multicolumn{3}{|c|}{ Inoculum $0 . \mathrm{D} .=0.5$} & \multicolumn{2}{|c|}{ Inoculum $0 . \mathrm{D} .=0.0005$} \\
\hline & Aerobic & $\begin{array}{c}\text { Aerobic } \\
+\mathrm{CO}_{2}\end{array}$ & $\begin{array}{c}\text { Anaerobic } \\
+\mathrm{CO}_{2}\end{array}$ & $\begin{array}{c}\text { Aerobic } \\
+\mathrm{CO}_{2}\end{array}$ & $\begin{array}{c}\text { Anaerobic } \\
+\mathrm{CO}_{2}\end{array}$ \\
\hline $\mathbf{P} 1$ & 0.03 & $1 \cdot 58$ & $1 \cdot 65$ & $0 \cdot 03$ & $1 \cdot 49$ \\
\hline P2S & 0.01 & 0.96 & $1 \cdot 85$ & $0 \cdot 03$ & $\mathbf{1} \cdot 82$ \\
\hline P3R & $0 \cdot 03$ & $0 \cdot 63$ & $0 \cdot 65$ & 0.07 & $\mathbf{1} \cdot 85$ \\
\hline P3S & 0.01 & $\mathbf{1} \cdot 63$ & 1.82 & 0.01 & $\mathbf{1} \cdot \mathbf{8 8}$ \\
\hline P4 & 0.07 & $1 \cdot 30$ & $1 \cdot 66$ & 0.07 & $1 \cdot 60$ \\
\hline A1 & $0 \cdot 04$ & 0.53 & $\mathbf{1 \cdot 2 1}$ & 0.02 & $\mathbf{1} \cdot \mathbf{3 9}$ \\
\hline A 8 & 0.07 & $2 \cdot 00$ & $1 \cdot 25$ & 0.01 & $1 \cdot 11$ \\
\hline $\mathbf{A 9}$ & 0.02 & $1 \cdot 10$ & $2 \cdot 00$ & $0 \cdot 00$ & $2 \cdot 00$ \\
\hline A 10 & 0.01 & 0.02 & $1 \cdot 30$ & 0.01 & $1 \cdot 33$ \\
\hline A12 & 0.02 & 0.00 & $0 \cdot 92$ & $0 \cdot 02$ & $1 \cdot 47$ \\
\hline A 601 & $0 \cdot 01$ & $2 \cdot 00$ & $\mathbf{2 \cdot 0 0}$ & 0.00 & $\mathbf{2 \cdot 0 0}$ \\
\hline
\end{tabular}

exhibited by some strains of Actinomyces (Howell \& Pine, 1956), which were subsequently identified as Actinomyces naeslundii (Howell et al. 1959). It was in general much more rapid than the growth exhibited by the typical $A$. israelii strains.

As shown in Table 4, large inocula of most strains grew in air when the concentration of carbon dioxide was increased. However, small inocula required anaerobic conditions for growth. Neither the rates of growth nor yields of organisms formed by strains of Actinomyces bovis (except strain A 8) were greater in the presence of air + carbon dioxide than anaerobically. This result distinguishes $A$. bovis from strains now recognized as $\boldsymbol{A}$. naeslundii, which may show an increased amount of growth when carbon dioxide + air are present (Pine \& Howell, 1956).

General physiological characteristics. Excepting strain A601, all strains, whether smooth or rough variants, exhibited the same general physiological characteristics. They were catalase negative, did not liquefy gelatin in the presence or absence of glucose, did not reduce nitrate to nitrite and did not form hydrogen sulphide or indole. The production of acetoin was variable. Litmus milk was often reduced, 
but little if any acid curd was formed. The casein was never coagulated or peptonized. None of the strains grew in $4 \%(\mathrm{w} / \mathrm{v})$ sodium chloride or in $20 \%(\mathrm{w} / \mathrm{v})$ bile.

Perhaps the most striking physiological character observed in the Actinomyces bovis strains as compared with the human strains was their ability rapidly to hydrolyse and ferment starch and to use it as a carbon source for growth. The amount of starch hydrolysis in 24-72 hr. by human strains was negligible or limited to immediate vicinity of the colonies; the bovine strains gave total hydrolysis of streak plates or slants within 24-48 hr. When agar plates of maintenance medium with $0.5 \%(\mathrm{w} / \mathrm{v})$ starch and no added glucose were streaked with Actinomyces strains, all of the strains of $A$. bovis grew in 3 days and when tested with $\mathrm{KI}+\mathrm{I}$ solution showed complete hydrolysis of the starch. On the other hand, strain A601 behaved similarly to the human strains. The human strains either failed to grow, grew poorly with no hydrolysis of the starch, or grew slowly with very limited zones of hydrolysis surrounding heavy areas of growth. In Casitone broth in which $\mathbf{0 . 5} \%$ starch replaced the glucose, all the strains of $A$. bovis hydrolysed starch and formed acid (Table 5). However, none of the human strains of Actinomyces turned the medium acid, although cultures $\mathrm{OS} 131,286,279$ and 283 effected some hydrolysis of starch as indicated by the formation of a deep red iodine-starch complex. Strain A601 did not grow on this medium.

The strains of Actinomyces bovis formed a homogeneous group which gave acid but no gas with glucose and starch (Table 5). They formed acid from fructose, maltose, lactose, and sucrose less consistently, half of the strains fermented mannose and an occasional strain attacked glycerol. None of the other carbohydrates tested gave acid or gas. In contrast, strain A601 gave strong acid formation with fructose, maltose, lactose, sucrose, mannose, xylose, ribose, raffinose and salicin. Rhamnose gave some acid; there was no acid from starch. This result with strain A601 is similar to the results obtained previously with the various human strains (Pine \& Howell, 1956; Howell et al. 1959). These results, its microcolony morphology, and other characteristics justified the conclusion that strain A601 was a strain of $A$. israelii.

Twenty to $29 \mu$ mole glucose were fermented by 9 strains of Actinomyces bovis with the formation of formic acid (6-9 $\mu$ mole); acetic acid $(6-10 \mu$ mole), succinic acid (5-12 $\mu$ mole) and lactic acid (31-49 $\mu \mathrm{mole})$; carbon recoveries ranged from 86 to $103 \%$. Isolation and determination of the specific rotation of the lactic acid of $A$. bovis, strain A 12, showed that the acid was $\mathrm{L}(+)$ lactic acid. These are the same products as reported previously for the human strains of Actinomyces (Pine \& Howell, 1956). As shown previously for human strains, there was an uptake of carbon dioxide during growth of $\boldsymbol{A}$. bovis.

\section{DISCUSSION}

Cohn (1875) first observed and described a branching filamentous micro-organism in the concretions taken from a lacrimal canal. This organism, now recognized as Actinomyces israelii (Smith, 1953; Pine \& Hardin, 1959) was named Streptothrix foersterii. This statement raises a question of taxonomic priority. However, the genus name Streptothrix is invalid since it was originally used for a different genus of fungi by Corda in 1839 (Breed \& Conn, 1919). The name Streptothrix (Cohn, 1875) 
is listed as a synonym for Streptomyces in Bergey's Manual, 6th and 7th ed. To the best knowledge of the senior author, no species of Norcardia or Streptomyces has been identified as a cause of lacrimal canaliculitis, although these organisms have been responsible for other infections of the eye. Since it has been established that $A$. israelii is the primary cause of concretions in the lacrimal canal with subsequent lacrimal canaliculitis and blepharitis (Smith, 1953; Pine, Hardin, Roberts \& Turner,

\section{Table 5. Result of fermentation of specified sugars by bovine strains of Actinomyces}

$+=$ Acid, no gas, indicator (bromcresol purple) yellow, final pH 5.0-5.5. $\pm=$ indicator violet, moderate acid formation, final pH 5.5 to $6 \cdot 0$. - indicator purple (unchanged), little or no acid formation. Test tubes incubated 7 days at $37^{\circ}$. Duplicate values given are comparative results of two different laboratories. Basal medium was the casitone medium with $0.5 \%(\mathrm{w} / \mathrm{v})$ sugar.

\begin{tabular}{|c|c|c|c|c|c|c|c|c|}
\hline \multirow[b]{2}{*}{ Strain } & \multicolumn{8}{|c|}{ Substrate } \\
\hline & Glucose & Starch & Fructose & Maltose & Lactose & Sucrose & Mannose & Mannitol \\
\hline P1 &,++ & + & + &,++ &,++ &,++ & + &,-- \\
\hline P2R & + & + & + & & & & - & - \\
\hline P2S &,++ & + & + &,++ &,++ &,++ & + &,-- \\
\hline P3R &,++ & + & + &,++ &,++ &,++ & \pm &,-- \\
\hline P3S &,++ & + & + &, \pm \pm &,++ &,++ & - &,-- \\
\hline $\mathbf{P 4}$ &,++ & + & \pm &,$+ \bar{t}$ &,+- &,+ \pm & - &,-- \\
\hline A 1 &,++ & + & $\bar{t}$ &,++ &,+ \pm &,++ & - &,-- \\
\hline A 8 &,++ & + & - &,- \pm &,+ \pm &,++ & - &,-- \\
\hline A9 &,++ & + & + &, \pm \pm &,++ &,-+ & \pm &,-- \\
\hline A 10 &,++ & + & + &, \pm \pm &,+ \pm &,-+ & + &,-- \\
\hline A 11 &,++ & + & + &, \pm- &,++ &,++ & - &,-- \\
\hline A12 &,++ & + & + &,+- &,+ \pm &,-+ & + &,-- \\
\hline \multirow[t]{2}{*}{ A601 } &,++ & - & + &,++ &,++ &,++ & + &,-- \\
\hline & \multicolumn{8}{|c|}{ Substrate } \\
\hline Strain & Xylose & Arabinose & Ribose & Raffinose & Inulin & Salicin & Glycerol & Rhamnose \\
\hline P1 &,-- & - & - & - & - &,-- & - & - \\
\hline P2R & - & - & - & - & - & - & - & - \\
\hline P2S &,-- & - & - & - & - &,-- & - & - \\
\hline P3R &,-- & - & - & - & - &,-- & - & - \\
\hline P3S &,-- & - & - & - & - &,-- & - & - \\
\hline P4 &,-- & - & - & - & - &,-- & - & - \\
\hline A1 &,-- & - & - & - & - &,-- & - & - \\
\hline A 8 &,-- & - & - & - & - &,-- & - & - \\
\hline A9 &,-- & - & - & - & - &,-- & - & - \\
\hline A 10 &,-- & - & - & - & - &,-- & - & - \\
\hline A11 &,-- & - & - & - & - &,-- & \pm & - \\
\hline A 12 &,-- & - & - & - & - &,-- & $=$ & - \\
\hline A 601 &,+- & - & + & + & - &,++ & - & \pm \\
\hline
\end{tabular}

1960) it is our opinion the species name foersterii has priority over israelii. However, we feel that common usage warrants the continuation of the present nomenclature.

Shortly after the description made by Cohn, Harz (1879) described in detail a similar organism in granules observed in tissues of cows with lumpy jaw. Previously, he had named this organism Actinomyces bovis (Harz, 1877). Neither Cohn nor Harz cultured the organisms observed by them, and it was not until approximately 10 years later that the organism was isolated and cultured anaerobically from lumpy jaw of cow by Mosselman \& Liénaux (1890) and from actinomycosis of man by 
Wolff \& Israel (1891). Because of the pathological relationships of the two diseases as shown by Israel (1878) and Ponfick (1880) and the similarity in the formation of granules in tissue, it was considered that the organisms causing these diseases were the same. This opinion was later supported by Silberschmidt (1901) who compared the cultural and morphological characteristics of pure cultures taken from a case of lacrimal infection of man, thoracic and maxillary actinomycosis in man, and lumpy jaw of a cow; and by Wright (1905) who compared two cultures isolated from two cases of lumpy jaw of cows with 13 cultures taken from actinomycosis in man. Both investigators considered the strains isolated from man and cow to be identical. Consequently, after the taxonomic validity of the name had been established by Breed \& Conn (1919), the name $A$. bovis was applied to all strains of anaerobic actinomycetes isolated from actinomycosis of man or animals.

Erikson (1940) compared 5 strains of Actinomyces bovis, isolated from infected cows, with 15 strains isolated from human sources. She found that the bovine strains formed a homogeneous group which, without exception, produced only minute, flat, smooth, soft colonies on adequate media. Microscopic examination of the margins of these colonies did not reveal the irregular radiating outgrowths characteristic of the human strains as a whole; instead, they showed an almost entire margin. When extrusion of filaments did occur, it took place in a sinuous arrangement and not in the usual radiating pattern. On the basis of these results and the facts that growth in liquid was more turbid, that the animal strains were more oxygen tolerant, and that these strains had a lesser ability to ferment salicin and mannitol, she divided the genus into two species. $A$. bovis was the name applied to the smooth animal strains; whereas, $A$. israelii Kruse was used for the strains isolated from man. The association of the smooth $A$. bovis with pulmonary actinomycosis in swine was established by Vawter (1946), who also pointed out the absence of myceloid or filamentous colonies. Subsequently, Thompson (1950) isolated 11 strains of $A$. bovis from cattle with lumpy jaw and compared them, in very limited experiments, with 8 strains isolated from human infections. All of the strains isolated from cows formed smooth round colonies after 6-7 days except one which was identical with the rough strains of man. However, contrary to the results of Erikson (1940), Thompson (1950) observed that the very young colonies were composed of mycelial elements which radiated from the centre of the colony. The strains of $A$. bovis grew diffusely in thioglycollate medium, although in brain broth growth was slow and limited to the bottom of the tube. On the basis of his studies, Thompson (1950) concluded that Erikson's separation of Actinomyces into the two species was justified.

Later, Thompson \& Lovestedt (1951) described strains of Actinomyces which grew in air on primary isolation. Subsequently these strains formed rough and smooth colonies and grew rapidly and profusely on suitable media. For this group, they proposed the name Actinomyces naeslundi. Recently, Howell et al. (1959) have more clearly defined and delineated this group, for which they also support the name A. naeslundii.

However, the results of many investigators emphasized that colonial and cultural descriptions of many strains of Actinomyces spp. were subject to variation with changes in medium or conditions of growth (Rosebury, 1944). In addition studies by Slack, Spears, Snodgrass \& Kuchler (1955) indicated that Actinomyces isolated 
from horse, cow, pig, and man could not be differentiated immunologically. Some investigators, therefore, have not considered the difference between Actinomyces bovis and $A$. israelii to be sufficiently great to warrant species separation and continued to use the single name $A$. bovis for all strains, even though such species separation was given in Bergey's Manual, 6th (1948) and 7th (1957) editions. Indeed, this was also our opinion at the initiation of this work.

However, when we first observed the entire dew-drop colonies of Actinomyces bovis on isolation plates they were strikingly different from the small mycelial colonies which we anticipated from human cases of actinomycosis. Consequently, there was no complete assurance that these were, indeed, strains of Actinomyces until each culture was later observed to form typical actinomycotic mycelium when inoculated into hamsters or mice. The original colonies were chosen because they represented the majority of the colonies observed or were the only organisms isolated, were catalase negative, and were made up of Gram-positive diphtheroid elements. These forms were then recognized as being related to forms of $A$. israelii and $A$. naeslundii, but additional studies emphasized differences in animal pathogenicity, cellular morphology and fermentation of carbohydrates. In addition, a high rate of change from smooth to rough or rough to smooth was common to most of the strains of $A$. bovis, but not observed with strains of $A$. israelii.

Erikson (1940) also reported that human strains of Actinomyces failed to form smooth colony variants. However, Lentze (1938) isolated rough and smooth strains from human cases of actinomycosis and by direct observation of single microcolonies observed the conversion of rough colonies to smooth colonies. The colonies described by Lentze as type II $a$ were morphologically identical to the smooth colonies of our Actinomyces bovis strains. However, the colony forms of the typical Wolff-Israel Actinomyces described and photographed by Lentze were essentially identical to the $A$. israelii strains which we have depicted. Rosebury, Epps \& Clark (1944) have also described what may have been a rough to smooth variation.

Vawter (1946) described the colonies formed by strains isolated from pulmonary actinomycosis of swine as being opalescent, pulvinate, homogeneous forms with smooth edges. Myceloid or filamentous colonies were not observed on agar plate cultures. The colonies photographed by Vawter (1946) were identical with those in our Fig. 12 (Pl. 2); he did not report any colony variation.

Thompson (1950) did not observe smooth to rough conversion in any of the bovine strains he isolated, although Thompson \& Lovestedt (1951) have described rough to smooth and smooth to rough change in Actinomyces naeslundii. Such colonial variation was not described by Magnusson (1928) for his type A, isolated from cows. However, Magnusson (1928) reported two types of cultures isolated from infected sow udders. One, type B, was typical of the cultures described by Wright (1905) for $A$. bovis, being hard, granular, and strongly adherent to the surface of the agar medium. The second type (type $\mathrm{C}$ ) was soft, succulent, and irregularly round, and the colonies were 5 to 10 times larger than those of type B. Types $\mathbf{B}$ and $\mathbf{C}$ were found together in the same abscess in 11 cases, while $B$ was found alone in 99 cases, and $\mathbf{C}$ was found alone in 71 cases. Unfortunately, cultural and colony descriptions of these strains were limited; no photographs of the colonies were presented, and, due to the inability to grow the isolates, few physiological data were obtained. Consequently, the colonial and physiological relationships of types $\mathrm{A}$, isolated from 
cows, and $\mathrm{B}$ and $\mathrm{C}$, isolated from swine to the smooth and rough forms of the bovine strains described here cannot be ascertained.

Although colony changes of any given strain may be readily observed, the factors and the interrelationships responsible for such changes are not, by any means, completely understood. When such changes occurred, the rough microcolonies of Actinomyces bovis still did not show a true radiating mycelium as did $A$. israelii colonies. On the other hand, $A$. naeslundii, which generally forms colonies having true mycelium, will sometimes form small microcolonies indistinguishable from those of $A$. bovis (Howell et al. 1959). However, other characters readily separate this proposed species from $A$. bovis. Further identification by means of colony morphology may be made by the use of brain heart infusion agar. The ability of brain heart infusion agar to support the appearance of smooth forms of $A$. bovis has been so consistent on primary isolation from animals or primary transfer from the maintenance medium that it serves as a valuable diagnostic aid for separating $A$. bovis from $A$. israelii, even though brain heart infusion agar itself fails to maintain cultures beyond a few transfers (Pine \& Watson, 1959).

The results of sugar fermentation studies reported by Ludwig \& Sullivan (1952), King \& Meyer (1957) and Hazen \& Little (1958) for bovine isolates are not in agreement with our findings. However, one of the two bovine isolates described by King \& Meyer, A 601, has been identified by us as Actinomyces israelii. Neither Thompson (1950) nor Magnusson (1928) gave data on sugar fermentations. On the other hand, our data are in agreement with those of Erikson (1940) for bovine strains but not with the very limited data of Menges, Larsh \& Habermann (1953) in a case of canine actinomycosis in that their strain failed to ferment lactose. The fermentative results of Vawter (1946) with a strain isolated from swine differ from the results we obtained with bovine strains since the swine strain did not ferment starch. The bovine strains tested by him fermented sugars which were not fermented by our strains (Vawter, 1933). In addition, it reduced nitrate to nitrite. Kimball, Twiehaus \& Frank (1954) ultimately showed that the Actinomyces strains reported by them to cause equine fistulous withers were catalase positive and therefore the sugar fermentative data (Kimball \& Frank, 1945) cannot be considered as applicable to Actinomyces (Suter, 56). The remaining physiological data reported herein for Actinomyces spp. substantiate the homogeneity of the genus, there being little to separate the species $A$. bovis, $A$. israelii and $A$. naeslundii. However, no strain of $A$. bovis reduced nitrate to nitrite; all of the strains of $A$. naeslundii used here or described previously (Howell et al. 1959) did reduce nitrate to nitrite, while this characteristic was variable in strains of $\boldsymbol{A}$. israelii.

Cummins \& Harris (1958) reported the results of cell-wall studies of members of the Actinomycetales and related groups. In this study it was found that strains of Actinomyces typical of Actinomyces israelii contained galactose, glucosamine, muramic acid, and the amino acids alanine, glutamic acid and lysine. Strains isolated from cows, however, contained rhamnose, sugar component ' $\mathbf{P}$ ', glucosamine, muramic acid and aspartic acid in addition to the amino acids alanine, glutamic acid and lysine. In some strains small amounts of galactose were also present. On request our bovine strains were sent to Dr Cummins, who determined the cell-wall composition and compared the results with those reported previously (Cummins \& Harris, 1959). Again, it was found that on the basis of cell-wall studies, 
these cultures of $A$. bovis were essentially identical to the bovine strains studied originally. However, strain A601 gave an analysis typical of $A$. israelii strains.

In addition, Dr Cummins found no major difference between the rough and smooth variants (P2R, P2S and P3R, P3S) with the exception that P2S contained galactosamine and P2R had little if any aspartic acid (Cummins, 1959, personal communication). The results of Cummins \& Harris (1959) not only re-emphasize the validity of the separation of these groups as proposed by Erikson (1940), but also support our conclusion, based on physiological data, that lumpy jaw in our bovine case P2 was not the result of a mixed infection with Actinomyces israelii and $A$. bovis. In view of the fact that reproducible conversion of $\mathrm{P} 2 \mathrm{~S}$ to $\mathrm{P} 2 \mathrm{R}$, or vice versa, was not obtained, the question as to the origin of these two colonial types in the $\mathbf{P} 2$ case of lumpy jaw remains unresolved. If the rough form occurred as a variant of the smooth colony, the rough form would reflect not only a loss of galactos-

Table 6. Characters identifying Actinomyces species

\begin{tabular}{|c|c|c|c|}
\hline Character & A. israelii & A. naeslundii & A. bovis \\
\hline \multicolumn{4}{|l|}{$\begin{array}{l}\text { Morphology of microcolony } \\
(24-48 \mathrm{hr} .)\end{array}$} \\
\hline Aerobiosis & $\begin{array}{l}\text { Anaerobic to } \\
\text { micro- } \\
\text { aerophilic }\end{array}$ & $\begin{array}{c}\text { Facultative in } \\
\text { presence of } \\
\text { increased } \mathrm{CO}_{2}\end{array}$ & $\begin{array}{c}\text { Anaerobic to } \\
\text { micro- } \\
\text { aerophilic }\end{array}$ \\
\hline Maximum growth* reached in & 3-7 days & 1 day & 2-3 days \\
\hline Catalase & - & - & - \\
\hline Gelatin liquefaction & - & - & - \\
\hline Starch hydrolysis &,+- &,+- & +10 \\
\hline \multicolumn{4}{|l|}{ Acid but no gas formed: $\dagger$} \\
\hline Glucose & + & + & + \\
\hline Xylose & $+(-)$ & - & - \\
\hline Mannitol & $+(-)$ & - & - \\
\hline Raffinose &,-+ & + & - \\
\hline Starch & $-(+)$ & $-(+)$ & + \\
\hline Nitrate reduced to nitrite & $+(-)$ & + & - \\
\hline
\end{tabular}

amine, and a partial loss in aspartic acid in the cell wall, but also a requirement for growth factors, some of which are present in brain heart infusion but are not in the Casitone medium.

Based on the results of Silberschmidt (1901), Wright (1905), Thompson (1950), and the results presented here with strain A601, there can be little doubt that Actinomyces israelii may be a cause of lumpy jaw in cattle. However, based on our results and those cases adequately described in the literature, the number of cases due to this species is small in comparison with the bovine infections caused by $\boldsymbol{A}$. bovis. On the other hand, with the exception of the work reported by Lentze (1938) and Holm (1948), there is little evidence suggesting that $A$. bovis can cause actinomycosis in man.

In the many animal experiments done with mice and hamsters, the impression is obtained that the human strains of Actinomyces are more pathogenic than the 
bovine strains. This impression is a result of general observation of the mycelium formed in tissues and of the relative numbers of progressive infections resulting from animal inoculations. But as shown by Table $\mathbf{3}$, only $\mathbf{5}$ human strains formed an extensive infection. Therefore, any conclusion as to relative pathogenicity of the bovine and human isolates is limited by the erratic nature and by the very low percentage of infections caused by any member of the genus (Miller \& Drake, 1951; Rosebury, 1944).

On the basis of the results reported here and previously (Pine \& Howell, 1956; Howell et al. 1959) and by others (Erikson, 1940; Thompson, 1950; Thompson \& Lovestedt, 1951), three main groups of Actinomyces can be differentiated from each other by the characters listed in Table 6.

A preliminary report of this work was published by the authors in Bact. Proc. 1960 , p. 79. The authors wish to express their appreciation to Mr C. M. Bishop, Department of Pathology, Duke University Medical School, for the photographs used in this publication; to Dr G. Bullock, New Bern, North Carolina, who supplied us with the infected bovine heads, P1, P2, P3 and P4; and to Drs L. Ajello, W. Kaplan and Lucille K. Georg, Communicable Disease Center, Chamblee, Georgia, for their cultures, references, time and experience so generously contributed during a visit to their laboratories; and to Mr W. C. Murphy, III, NIDR, for his valuable technical assistance. The studies reported in this paper were supported in part by Grant E1866 from the National Institute of Allergy and Infectious Diseases, United States Public Health Service, Bethesda, Maryland.

\section{REFERENCES}

Bergey's Manual of Determinative Bacteriology (1948). 6th ed. Ed. R. S. Breed, E. G. D. Murray \& A. P. Hitchens. Baltimore: The Williams and Wilkins Company.

Bergey's Manual of Determinative Bacteriology (1957). 7th ed. Ed. R. S. Breed, E. G. D. Murray \& N. R. Smith. Baltimore: The Williams and Wilkins Company.

Breed, R. S. \& ConN, H. J. (1919). The nomenclature of the Actinomycetaceae. J. Bact. 4, 585 .

CoHn, F. (1875). Untersuchungen über Bacterien. Beitr. Biol. Pfl. 2, 186.

Conant, N. F., Smith, D. T., Baker, R. D. Calloway, J. L. \& Martin, D. S. (1954). Manual of Clinical Mycology, 2nd ed. Philadelphia: W. B. Saunders Company.

Cummins, C. S. \& Harris, H. (1958). Studies on the cell-wall composition and taxonomy of Actinomycetales and related groups. J. gen. Microbiol. 18, 173.

Cummins, C. S. \& Harris, H. (1959). Cell-wall composition in strains of Actinomyces isolated from human and bovine lesions. J. gen. Microbiol. 21, ii.

Emmons, C. W. (1935). Actinomyces and actinomycosis. Puerto Rico J. publ. Hlth, $11,63$.

Erikson, D. (1940). Pathogenic anaerobic organisms of the Actinomyces group. Spec. Rep. Ser. med. Res. Coun., Lond. no. 240.

Harz, C. O. In Bollinger, O. (1877). Über eine neue Pilzkrankheit beim Rinde. Z Zbl. med. Wiss. 15, 481.

Harz, C. O. (1879). Actinomyces bovis, ein neuer Schimmel in den Geweben des Rindes. Dtsch. Z. Tiermed, 5, 125.

Hazen, E. L. \& LitTle, G. N. (1958). Actinomyces bovis and 'anaerobic diphtheroids': pathogenicity for hamsters and some other differentiating characteristics. J. Lab. clin. Med. 51, 968.

HoLm, P. (1948). Some investigations into the penicillin sensitivity of human-pathogenic actinomycetes. Acta path. microbiol. Scand. 25, 376. 
Howell, A., Jun., Murphy, W. C. III, Paul, F. \& Stephan, R. M. (1959). Oral strains of Actinomyces. J. Bact. 78, 82.

Howell, A., Jun. \& Pine, L. (1956). Studies on the growth of species of Actinomyces. I. Cultivation in a synthetic medium with starch. J. Bact. 71, 47.

Israel, J. (1878). Neue Beobachtungen auf dem Gebiete der Mykosen des Menschen. Virchores Arch. 74, 15.

Krmball, A. \& Frank, E. R. (1945). The isolation of Actinomyces bovis from fistulous withers and poll evil. Amer. J. vet. Res. 6, 39.

Kimball, A., Twiehaus, M. J. \& Frank, E. R. (1954). Actinomyces bovis isolated from six cases of bovine orchitis. A preliminary report. Amer. J. vet. Res. 15, 551.

KING, S. \& MEYER, E. (1957). Metabolic and serologic differentiation of Actinomyces bovis and 'anaerobic diphtheroids'. J. Bact. 74, 234.

Lentze, F. A. (1938). Zur Bakteriologie und Vakzinetherapie der Aktinomykose. Zbl. Bakt. 141, 21.

Ludwig, T. G. \& Sullivan, H. R. (1952). Studies of the flora of the mouth. VIII. An examination of selected human strains of anaerobic Actinomyces. Aust. J. exp. Biol. med. Sci. 30, 81.

Magnusson, H. (1928). The commonest forms of actinomycosis in domestic animals and their etiology. Acta path. microbiol. scand. 5, 170.

Menges, R. W., Larsh, H. W. \& Haberman, R. J. (1953). Canine actinomycosis. J. Amer. vet. med. Ass. $122,73$.

Muller, N. G. \& Drake, C. H. (1951). Experimental actinomycosis. Mycopath. Mycologia App. 6, 28.

Mosselman, G. \& Liénaux, E. (1890). L'actinomycose et son agent infectieux. Ann. Med. vet. 39, 409.

Pine, L. \& Hardin, H. (1959). Actinomyces israelii, a cause of lacrimal canaliculitis in man. J. Bact. 78, 164.

Pine, L., Hardin, H., Roberts, S. S. \& Turner, L. (1960). Actinomycotic canaliculitis. A report of two cases with a review of the characteristics which identify the causal organism, Actinomyces israelii. Amer. J. Ophthal. 49, 1278.

Pine, L. \& Howell, A. JUn. (1956). Comparison of physiological and biochemical characters of Actinomyces spp. with those of Lactobacillus bifidus. J. gen. Microbiol. 15, 428.

Pine, L. \& Watson, S. J. (1959). Evaluation of an isolation and maintenance medium for Actinomyces species and related organisms. J. Lab. clin. Med. 54, 107.

Ponfick, E. (1880). Über Actinomykose. Berl. klin. Wschr. 17, 660.

RosebURY, T. (1944). The parasitic actinomycetes and other filamentous microorganisms of the mouth. A review of their characteristics and relationships of the bacteriology of actinomycosis and of salivary calculus in man. Bact. Rev. 8, 189.

Rosebury, T., Eprs, L. J. \& Clark, A. R. (1944). A study of the isolation, cultivation, and pathogenicity of Actinomyces israelii recovered from the human mouth and from actinomycosis in man. J. infect. Dis. 74, 131.

Silberschmidt, W. (1901). Über Aktinomykose. Z. Hyg. InfektKr. 37, 345.

Slack, J. M., Spears, R. G., Snodgrass, W. G. \& Kuchler, R. J. (1955). Studies with microaerophilic actinomycetes. II. Serological groups as determined by the reciprocal agglutinin adsorption technique. J. Bact. 70, 400.

Smith, C. H. (1953). Ocular actinomycosis. Proc. R. Soc. Med. 46, 209.

Sundman, V. \& BJörksten, K. (1958). The globular involution forms of the bifid bacteria. J. gen. Microbiol. 19, 491.

SuTER, L. S. (1956). Evaluation of criteria used in the identification of Actinomyces bovis with particular reference to the catalase reaction. Mycopath. Mycologia App. 7, 220.

Thompson, L. (1950). Isolation and comparison of Actinomyces from human and bovine infections. Proc. Mayo Clin. 25, 81.

Thompson, L. \& Lovestedt, S. A. (1951). An actinomyces-like organism obtained from the human mouth. Proc. Mayo Clin. 26, 169.

VAwTER, L. R. (1933). A study of actinomycosis. Cornell Vet. 23, 126. (In Vawter, L. R., 1946). 

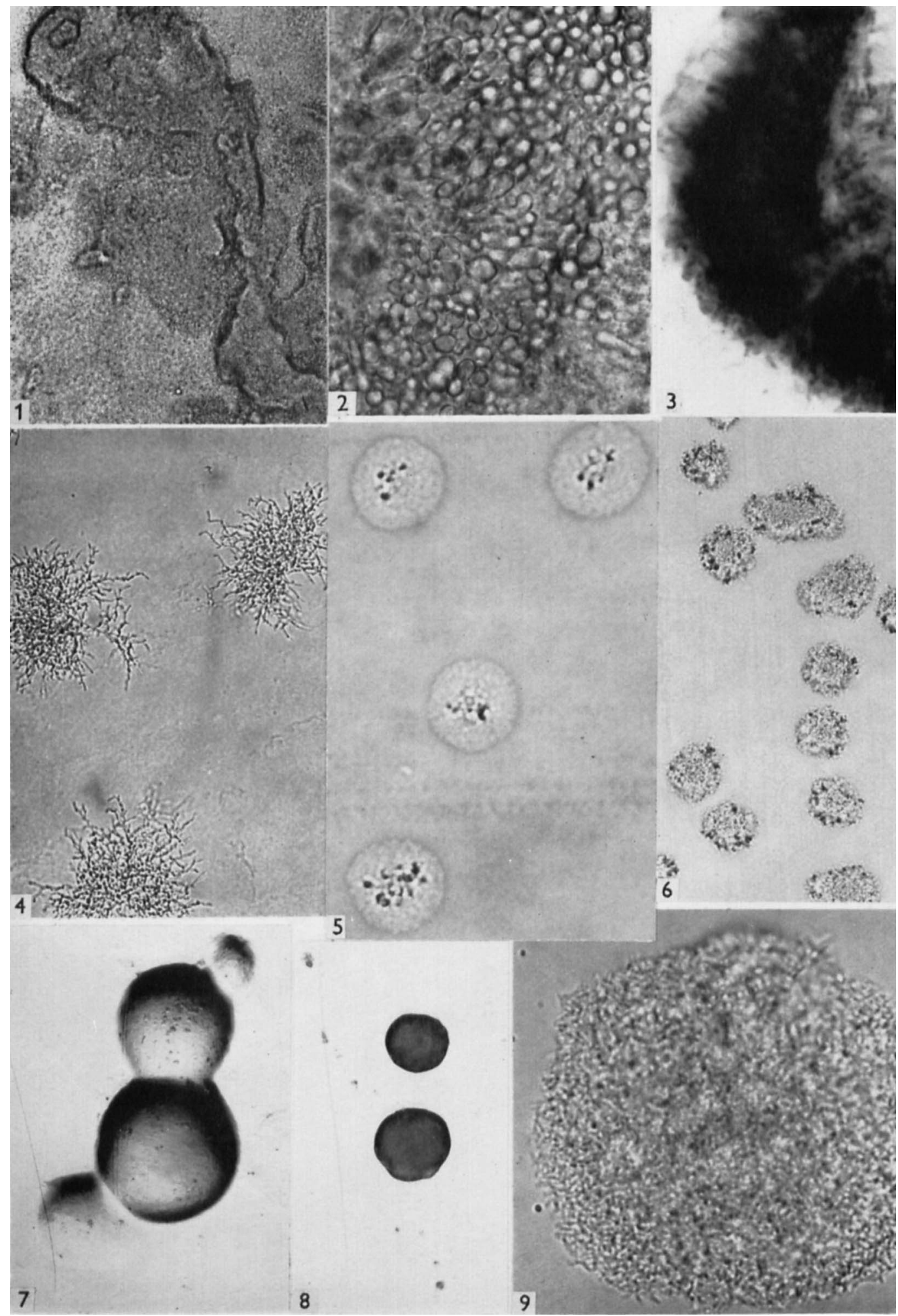
Journal of General Microbiology, Vol. 23, No. 3

Plate 2

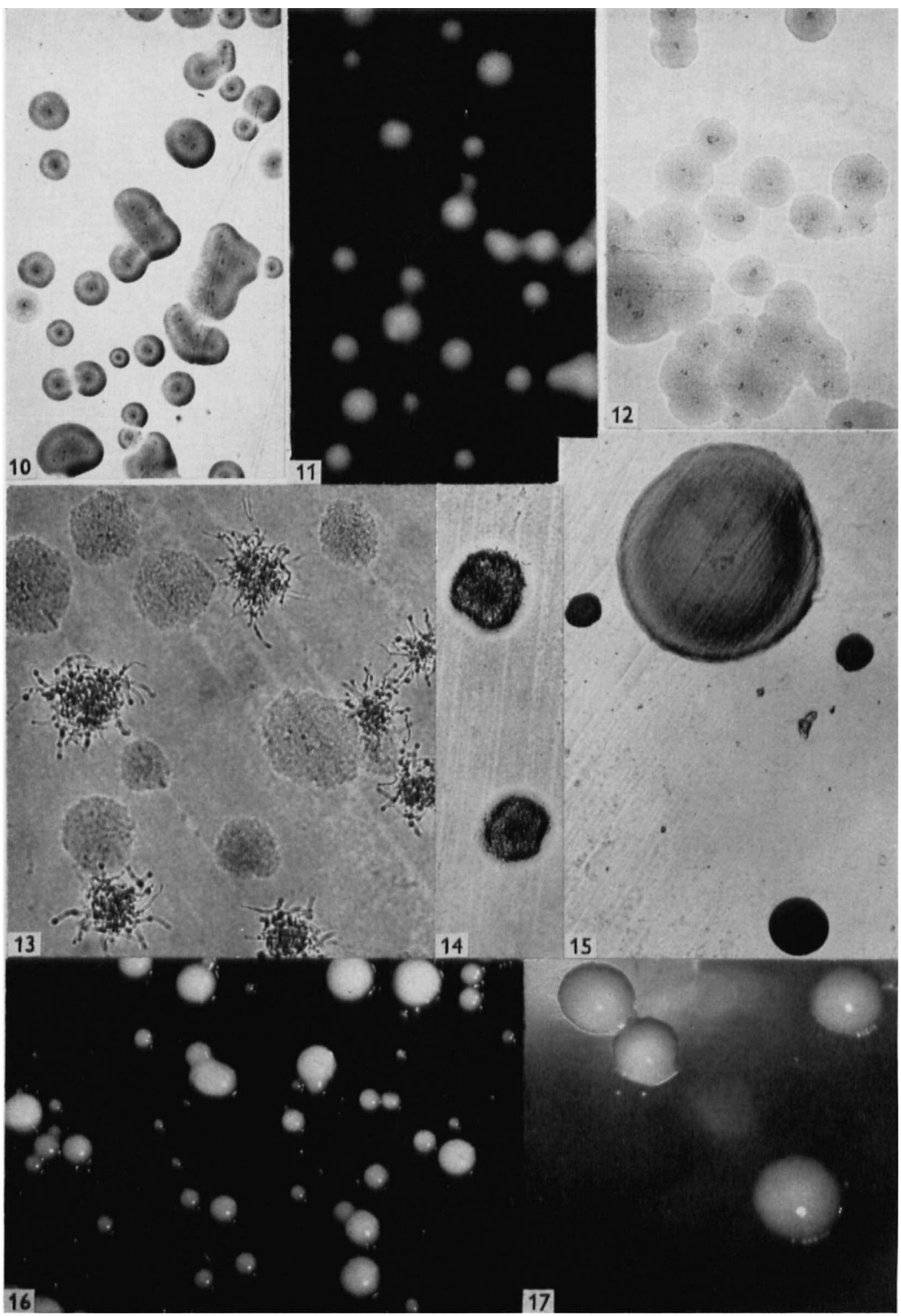

L. PINE, A. HOWELL AND S. J. WATSON 
Journal of General Microbiology, Vol. 23, No. 3

Plate 3

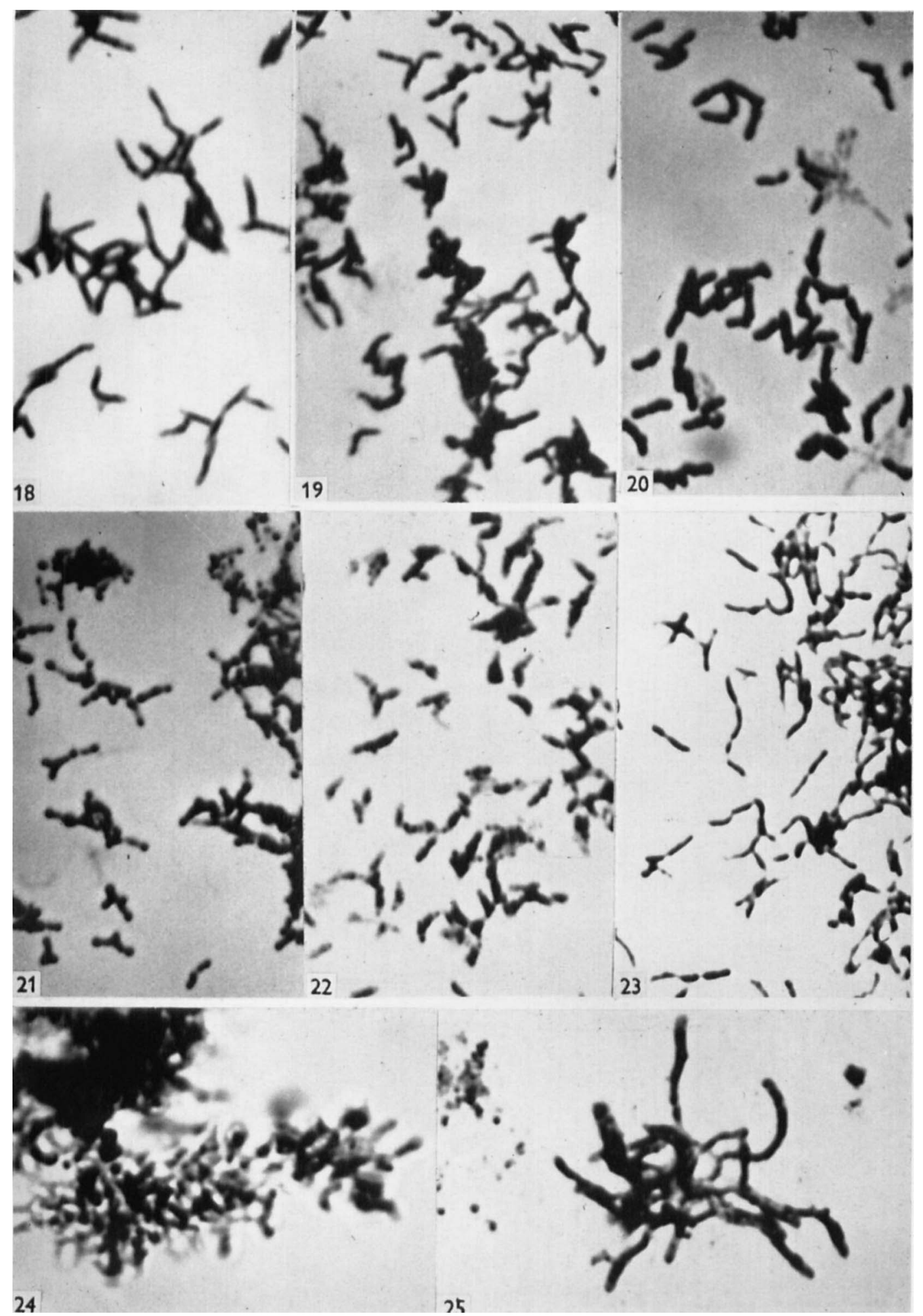

L. PINE, A. HOWELL aNd S. J. WATSON 

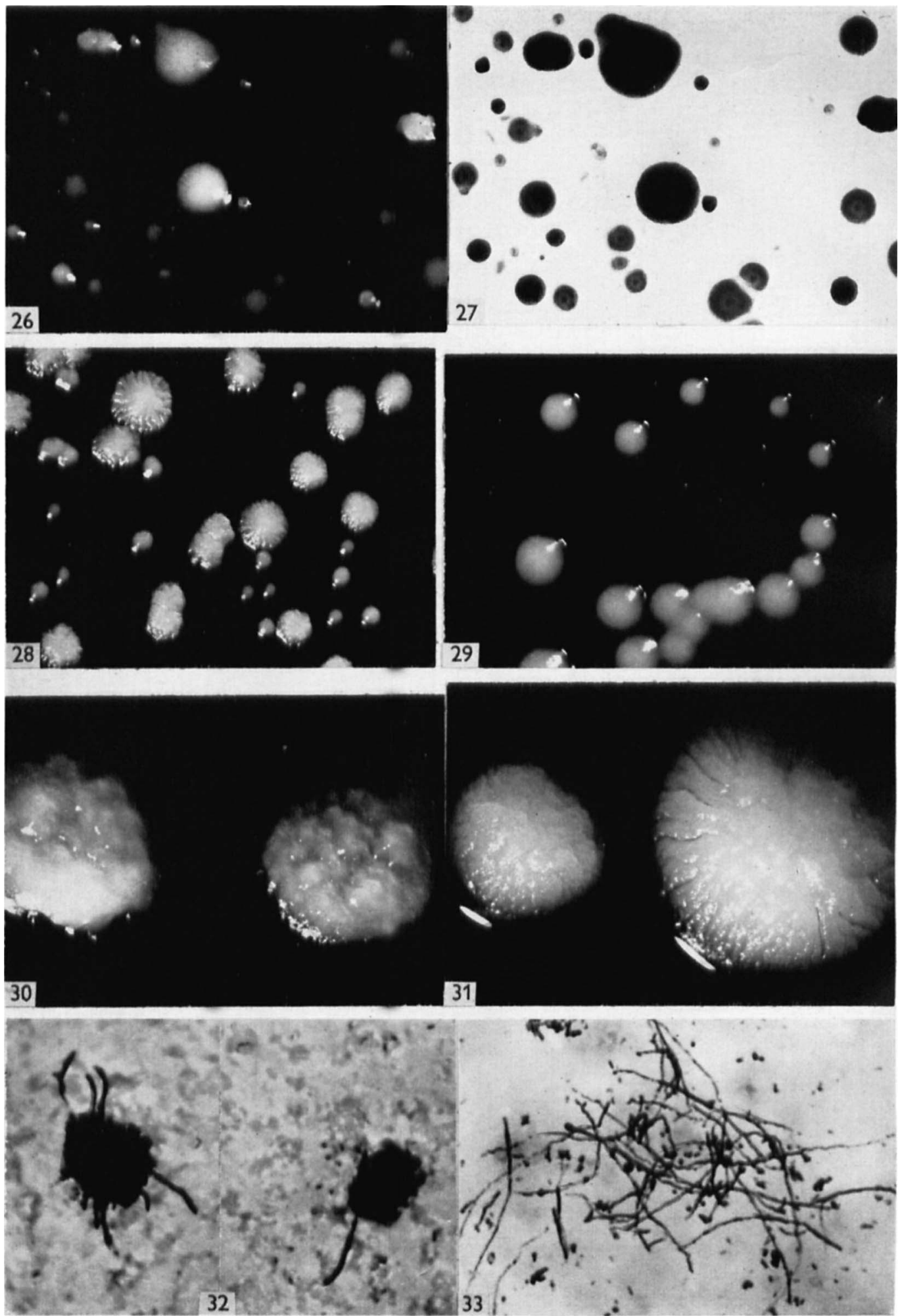

L. PINE, A. HOWELL AND S. J. WATSON 
Vawter, L. R. (1946). Pulmonary actinomycosis in swine. J. Amer. vet. med. Ass. 109, 198.

WoLfF, M. \& Israel, J. (1891). Ueber Reincultur des Actinomyces und seine Übertragbarkeit auf Thiere. Virchows Arch. 126, 11.

Wright, J. H. (1905). The biology of the microorganisms of actinomycosis. J. med. Res. 13, 349.

\section{EXPLANATION OF PLATES*}

\section{Plate 1}

Fig. 1. 'Sulphur' granule, case P1. (KOH mount.) $\times 115$.

Fig. 2. 'Sulphur' granules showing 'clubs'. Case P1. (KOH mount.) $\times 678$.

Fig. 3. 'Sulphur' granule, imbedded and sectioned. Case P1. Gram stain. $\times 450$.

Fig. 4. Actinomyces israelii, strain OS 131. Spider colonies. Brain heart infusion agar, transmitted light. $\times 300$.

Fig. 5. Actinomyces bovis, P3S. Brain heart infusion agar, transmitted light. $\times 290$.

Fig. 6. A. bovis, P3R. Brain heart infusion agar, transmitted light. $\times 171$.

Fig. 7. A. bovis, $\mathrm{P} 4 \mathrm{~S}$ and $\mathrm{P} 4 \mathrm{R}$ colonies. Isolation plate, Garrod's medium, oblique lighting. $\times 70$.

Fig. 8. A. bovis, P4R. Rough colonies on isolation plate. Maintenance medium, transmitted light. $\times \mathbf{7 0}$.

Fig. 9. A. bovis, P4R. Rough colony on maintenance medium, photographed under cover slip, transmitted light. $\times \mathbf{9 5 0}$.

\section{Plate 2}

Fig. 10. Actinomyces bovis, A11. Smooth colonies on brain heart infusion agar, transmitted and reflected light. $\times 13$.

Fig. 11. A. bovis, A11. Smooth colonies on brain heart infusion agar, reflected light. $\times 13$.

Fig. 12. A. bovis, P2S. Maintenance medium, transmitted and reflected light. $\times 70$.

Fig. 13. A. bovis, case P2. Primary isolation on maintenance medium. Rough (spider) and smooth colonies, transmitted light. $\times 290$.

Fig. 14. A. bovis, P2R. Later stage of development of spider colonies shown in fig. 13, transmitted light. $\times 170$.

Fig. 15. A. bovis, case P2. Primary isolation on Garrod's medium showing relative size of three rough colonies and one smooth colony after 5 days incubation. Transmitted and reflected light. $\times \mathbf{7 0}$.

Fig. 16. $A$. bovis, P2S. Seven-day colonies on maintenance medium, reflected light. $\times 13$.

Fig. 17. A. bovis, P2R. Fourteen-day colonies on maintenance medium, reflected light. $\times 45$.

\section{Plate 3}

Fig. 18. Actinomyces israelii, 534. Branching bacillary elements, grown in maintenance broth. Gram stain. $\times 1100$ enlarged to $\times 2200$.

Fig. 19. A. israelii, OS131. Branching diphtheroid elements, grown in maintenance broth. Gram stain. $\times 1100$ enlarged to $\times 2200$.

Fig. 20. Actinomyces bovis, A 12. Branching diphtheroid elements, grown in maintenance broth $24 \mathrm{hr}$. Gram stain. $\times 1100$ enlarged to $\times 2200$.

Fig. 21. A. bovis, A12. Branching diphtheroid elements, grown in maintenance broth $72 \mathrm{hr}$., showing metachromatic granules. Gram stain $\times 1100$ enlarged to $\times 2200$.

Fig. 22. A. bovis, P2S. Branching diphtheroid elements, grown in maintenance broth, $24 \mathrm{hr}$., showing amorphous cellular structures. Gram stain. $\times 1100$ enlarged to $\times 2200$.

Fig. 23. A. bovis, P2R. Fine branching bacillary elements of rough strain isolated from same cow as strain P2S. Maintenance broth, 4 days, Gram stain. $\times 1100$ enlarged to $\times 2200$.

* The macrocolonies photographed were 3-5 days old. 
Fig. 24. A. bovis, A11 R. Young mycelial clump grown 24 hr. in maintenance broth with $0.05 \%$ agar. Lactophenol-cotton blue mount. $\times 1100$ enlarged to $\times 2200$.

Fig. 25. A. bovis, A11 R. Young mycelial colony, grown $24 \mathrm{hr}$. in maintenance broth with $0 \cdot 05 \%$ agar. Gram stain. $\times 1100$ enlarged to $\times 2200$.

\section{Plate 4}

Fig. 26. Actinomyces bovis, A 11. Maintenance agar, reflected light. Same microscopic field as in fig. 27. Colonies having high lights were considered as rough colonies. $\times 13$.

Fig. 27. A. bovis, A 11. Maintenance agar, transmitted light. Same microscopic field as in fig. 26. Colonies showing concentric rings of transmitted light were considered as smooth colonies. Opaque colonies were rough colonies. $\times 13$.

Fig. 28. A. bovis, P3R. Stock culture, showing presence of smooth colonies. Maintenance agar, reflected light. Compare with fig. $6 . \times 13$.

Fig. 29. A. bovis, P3S. Stock culture. Note absence of rough colonies. Maintenance agar, transmitted light. $\times 13$.

Fig. 30. A. bovis, P3S. Effect of medium on macrocolony morphology. Thioglycollate agar, reflected light. $\times 29$.

Fig. 31. A. bovis, P3S. Effect of medium on macrocolony morphology. Inoculum same as that in fig. 30. Maintenance agar, reflected light. $\times 29$.

Fig. 32. A. bovine, P4R. Pus from hamster. Mycelial elements emanating from masses of cells. Gram stain. $\times 1100$.

Fig. 33. A. bovis, P2S. Pus from hamster. Gram stain. $\times 900$. 